\title{
A Survey of Stereotactic Body Radiation Therapy Use in the United States
}

Hubert Pan, M.S., Daniel R. Simpson, M.D., Loren K. Mell, M.D., Arno J. Mundt, M.D., and Joshua D. Lawson, M.D.

Department of Radiation Oncology Center for Advanced Radiotherapy Technologies University of California San Diego, La Jolla, CA

\section{Abstract}

BACKGROUND-Stereotactic body radiation therapy (SBRT) is a technique used to deliver high, ablative doses of radiation in a limited number of fractions to one or more extracranial target(s). The prevalence of SBRT use among radiation oncologists in the United States is unknown.

METHODS-A random sample of 1600 American radiation oncologists was surveyed via email and fax regarding SBRT usage, including year of adoption, motivations, disease sites treated, and common prescriptions used.

RESULTS-Of 1373 contactable physicians, 551 responses (40.1\%) were received. The proportion of physicians using SBRT was 63.9\% (95\% confidence interval: 60-68\%), of whom nearly half adopted it in 2008 or later. The most commonly cited reasons for adopting SBRT were to allow delivery of higher than conventional radiation doses $(90.3 \%)$ and to allow retreatment (73.9\%) in select patients. Academic physicians were more likely to report research as a motivation for SBRT adoption, whereas physicians in private practice were more likely to list competitive reasons. Among SBRT users, the most common disease sites treated were lung $(89.3 \%)$, spine $(67.5 \%)$, and liver $(54.5 \%)$ tumors. Overall, $76.0 \%$ of SBRT current users planned to increase their use, while $66.5 \%$ of nonusers planned to adopt the technology in the future.

CONCLUSIONS-SBRT has rapidly become a widely adopted treatment approach among American radiation oncologists. Further research and prospective trials are necessary to assess benefits and risks of this novel technology.

\section{Keywords}

stereotactic body radiotherapy; radiation oncology; survey

\section{Background}

Stereotactic body radiation therapy (SBRT) is a technique used to deliver high, ablative doses of radiation in a limited number of fractions to one or more extracranial target(s) 1,2 . SBRT has the potential to improve clinical outcomes of patients with a variety of primary and metastatic tumors, by allowing the delivery of higher than conventional doses and retreatment of previously irradiated patients.

Corresponding author: Joshua D. Lawson, M.D. Chief, Stereotactic Body Radiation Therapy Service Department of Radiation Oncology University of California San Diego 3855 Health Sciences Dr, MC0843 La Jolla, CA 92093-0843 Tel: 858-822-5129 / Fax: 858-822-6078 / jlawson@ucsd.edu.

Conflicts of Interest Disclosures: None 
While first used in the early 1990s3, increasing attention has been focused on SBRT in recent years, with encouraging results reported in a number of tumors sites including the lung4, spine5, and liver6. Despite this growing interest, little is known about the prevalence and use of SBRT in the radiation oncology community. While a previous survey was conducted in Japan focusing on SBRT in lung tumors7, no surveys have been performed assessing SBRT use in the United States.

We thus conducted and present here a nationwide survey of practicing American radiation oncologists regarding their SBRT usage, including year of adoption and disease sites treated, common prescriptions and technologies used, and underlying motivations for adoption.

\section{Methods}

\section{Study population}

A group of 1600 radiation oncologists was randomly selected from the approximately 5000 active members listed in the online American Society for Radiation Oncology (ASTRO) directory. All physicians who were designated as active and allied members were included. Emeritus professors and radiation oncologists practicing outside of the United States were excluded. The survey was sent in 2 forms: by email with a link to an online survey and by facsimile. If the email address and fax number were invalid, the physician was designated as uncontactable.

\section{Survey}

A 21-question survey was designed to obtain demographic information and the details of SBRT adoption and usage. For the purposes of this survey, SBRT was defined as: highprecision radiotherapy delivered in 5 or fewer fractions to very potent doses of highly conformal radiation with steep dose gradients around an extracranial target. Responses were collected between July 11 and September 7, 2010 and considered evaluable if at least partially completed.

All physicians were asked to supply information about their practice (type, size, specialty) and year graduated from residency. SBRT users were asked about year adopted, motivations, technologies, disease sites treated, common prescriptions, and future plans. Nonusers were asked about reasons behind not adopting SBRT and whether they intended to adopt SBRT in the future.

\section{Statistical Analysis}

The survey results are presented as the percentage of evaluable responses. Differences in proportions between groups were analyzed using chi-square tests. Significant values were defined as those with $\mathrm{P}<0.05$.

\section{Results \\ Study population}

Of the 1600 physicians surveyed, 1373 (85.8\%) were contactable (Fig. 1). From this, 551 (40.1\%) responded, including 21 that declined to participate and 20 that were retired, leaving 510 evaluable respondents.

Respondents represented physicians from 48 states and the District of Columbia (Table 1). Three hundred nineteen responses $(62.5 \%)$ were from private practice while the remaining $191(37.5 \%)$ were from academic physicians. The median practice size was 5 physicians (range: 1-60). The median time in practice was 16 years (range: 1-31). 
Of the 510 evaluable respondents, $63.9 \%$ (95\% confidence interval: 60-68\%) reported having used SBRT in their practice. As seen in Figure 2, approximately half of the current SBRT users adopted it in 2008 or later.

Experience with SBRT was more prevalent with physicians at academic centers as compared to those in private practice ( 70 vs $61 \% ; \mathrm{P}=0.04$ ), practices with more than 1 physician (67 vs 39\%; $\mathrm{P}<0.001$ ), physicians practicing $1-10$ years compared to $>10$ years ( 73 vs $59 \%$; $\mathrm{P}<0.01$ ), and those who identified themselves as specialists (71 vs $60 \%$; $\mathrm{P}=0.02)$. SBRT usage was similar across geographic regions of the West, South, East, and Midwest at 56\%, 63\%, 64\%, and 70\%, respectively ( $\mathrm{P}=0.13)$. SBRT was adopted more recently among private practice physicians, with a median start year of 2008 compared to 2007 for academic physicians.

The most common reasons for adopting SBRT were to allow delivery of higher than conventional radiation doses (90.3\%) and retreatment (73.9\%) in select patients (Fig. 3). Physicians in academic centers were more likely to cite clinical research as a motivation for SBRT adoption (59 vs $18 \%$; $\mathrm{P}<0.0001)$ whereas physicians in private practice were more likely to list gaining a competitive advantage or remaining competitive (42 vs $20 \%$; $\mathrm{P}<0.0001$ ) as reasons for adoption. Of the SBRT users, $76.0 \%$ reported plans to increase their use of SBRT and $21.7 \%$ plan to maintain the current level of use.

Most SBRT users (61.4\%) reported not using a stereotactic body frame (SBF). For those that reported using an SBF in their patients, its primary function was for immobilization (96.4\%). Overall, $13.3 \%$ of SBRT users reported using an SBF to establish an external coordinate system. For target localization, most SBRT users relied on image-guidance, with in-room volumetric imaging the most popular $(69.0 \%)$, followed by in-room planar imaging $(50.8 \%)$. Physicians at academic centers were more likely to use in-room volumetric (77 vs $64 \% ; \mathrm{P}=0.01$ ) and/or in-room planar imaging ( 61 vs $44 \% ; \mathrm{P}<0.01$ ) as compared to those in private practice.

\section{SBRT Disease Sites}

The cumulative adoption of SBRT among all respondents at the 3 most common disease sites of lung (51.8\%), spine (39.0\%), and liver (31.0\%) is shown in Figure 4. The majority of respondents who were using SBRT for lung, spine, and liver adopted it by 2008, 2007, and 2008, respectively. The largest yearly increase in cumulative adoption for all 3 disease sites occurred in 2009 (14.4\%, 8.1\%, and 8.7\% for lung, spine, and liver, respectively).

Lung was the most common disease site treated with SBRT (89.3\% of all users). A minority of physicians that have treated lung tumors (31.3\%) reported using fiducial markers. Fiducial usage was less common in academic centers compared to private practice (22 vs $38 \% ; \mathrm{P}<0.01)$. To manage respiratory-induced motion, physicians most commonly reported using abdominal compression (55.6\%) or respiratory gating (54.2\%), while breath hold techniques $(14.4 \%)$ and real-time tumor tracking $(15.3 \%)$ were less prevalent. The most commonly reported fraction number for lung tumor patients was 3 (47\%) (Table 2). For 3 fraction regimens, the most common doses are $20 \mathrm{~Gy} \mathrm{(46 \% )} \mathrm{or} 18 \mathrm{~Gy}(45 \%)$ per fraction to a median isodose line (IDL) of $80 \%$ (range: $70-100 \%$ ).

Spine was the second most common disease site treated with SBRT (67.5\% of the SBRT users). Fiducial markers were rarely used (12.4\%) in spine patients. The most commonly reported fraction number for spine tumor patients was $1(57 \%)$ (Table 2). For single fraction regimens, the most common prescription was $18 \mathrm{~Gy}(40 \%)$ or $16 \mathrm{~Gy}(34 \%)$ per fraction to a median IDL of $85 \%$ (range: 70-100\%) with a median maximum cord dose of $10 \mathrm{~Gy}$ (range: 
7-18 Gy). The median maximum cord dose was $4 \mathrm{~Gy}$ for both 3 and 5 fraction treatments with ranges of 3-6 Gy and 2-6 Gy, respectively.

Liver tumors were treated by $54.5 \%$ of SBRT users. Liver was the only disease site where fiducial markers were used by the majority (56.9\%) of respondents. Physicians commonly used respiratory gating (57.9\%) or abdominal compression (51.9\%) to manage respiratorinduced tumor motion. Alternative methods such as real-time tracking (17.2\%) and breath hold techniques (15.0\%) were not commonly used. The most commonly reported fraction number for liver tumor patients was $3(48 \%)$ (Table 2). For 3 fraction regimens, the most common dose was $15 \mathrm{~Gy}(40 \%)$ or $20 \mathrm{~Gy}(25 \%)$ per fraction to a median IDL of $80 \%$ (range: $70-100 \%)$.

The breakdown of disease sites currently treated by SBRT users is shown in Figure 5. In addition to the most common sites of lung, spine, and liver, 36.7\% of SBRT users reported having treated at least one other disease site. The most common other sites treated were the adrenal glands $(8.6 \%)$, pancreas $(8.6 \%)$, prostate $(7.9 \%)$, and retroperitoneum $(6.9 \%)$.

\section{SBRT Nonusers}

Among respondents who do not use SBRT, a majority (62.6\%) cited the lack of necessary equipment as a reason for their lack of adoption. The next most common reason was that a partner handles the SBRT cases (16.1\%), which was seen more frequently among physicians in academic centers ( 28 vs $11 \% ; \mathrm{P}<0.01)$.

A majority (66.5\%) of SBRT nonusers reported plans to adopt SBRT, a finding more common in private practice physicians ( $75 \mathrm{vs} 49 \%$; $\mathrm{P}<0.001)$. The most commonly cited reasons were to allow the delivery of higher than conventional doses $(84.1 \%)$ and to facilitate retreatment $(66.7 \%)$. Academic physicians were more likely to report research as a motivation for planned SBRT adoption $(41 \mathrm{vs} 13 \%$; $\mathrm{P}<0.001)$ whereas those in private practice were more likely to cite the desire to remain competitive (52 vs $16 \% ; \mathrm{P}<0.001)$.

\section{Discussion}

The objective of this study was to assess the current usage of SBRT in the United States. We found that SBRT is rapidly becoming a widely adopted treatment approach, currently employed by $63.9 \%$ of respondents, with nearly half having adopted it in 2008 or later. Use of SBRT will most likely increase in the coming years since approximately two-thirds of respondents who do not currently use SBRT reported planning to adopt it.

SBRT usage was more prevalent among physician respondents who practice in academic centers or non-solo practices. This is not surprising given the equipment and staffing requirements to clinically implement a new technology. Nevertheless, almost $40 \%$ of solo practitioners reported treating patients with SBRT, suggesting that the technology has become accessible to the broader radiation oncology community.

Consistent with the growing published literature, the 3 most common disease sites treated by SBRT users in this survey were lung $4,8^{-} 16$, spine $5^{,} 17^{-} 21$, and liver6, $22^{-2} 28$. Nonetheless, respondents also reported using SBRT in a variety of other disease sites with less published experience, including pancreas $29^{-} 32$, adrenal gland and retroperitoneum $33^{-} 36$, and prostate $37^{-} 42$.

In response to the query of common SBRT prescriptions, myriad fractionation and dose combinations were reported. Consistent with Radiation Therapy Oncology Group (RTOG) Trial 0236 , the most commonly reported lung prescription was $20 \mathrm{~Gy} \times 3^{4}$. Almost as 
frequently reported for lung tumor patients was $18 \mathrm{~Gy} \times 3$, which has been used in other studies9. The most commonly reported dose prescription from the Japanese survey of lung SBRT7 $(12 \mathrm{~Gy} \times 4)$ was the third most common among our responses. The most commonly reported dose prescription for SBRT of the spine was a single fraction of $18 \mathrm{~Gy}$, a dose lower than the mean dose of $20 \mathrm{~Gy}$ used in the largest available single institution series5. A dose of $18 \mathrm{~Gy}$ also does not reflect the results of another study that showed a dose response to $24 \mathrm{~Gy}$ as compared to $18-23$ Gy21. Liver SBRT showed the most variation in reported prescription doses, with the most common being $15 \mathrm{~Gy} \times 3$, consistent with the largest Phase II SBRT study of patients with colorectal metasases 25 .

Early implementations of SBRT included the use of an SBF to establish an external coordinate system3. However, in our survey, less than $15 \%$ of SBRT reported using a frame for stereotactic localization. In fact, the majority of SBRT users did not use a frame at all and instead rely upon image guidance. When an SBF was employed, its primary function was to provide immobilization only. Most physicians instead relied on in-room planar or volumetric imaging for target localization 43,44 .

A significant technical challenge in SBRT is accounting for respiratory-induced target motion45, 46. The majority of surveyed SBRT users addressed this problem in lung and liver tumor patients with the use of respiratory gating 47,48 or abdominal compression 49 , 50. Other methodologies such as active breathing control51 and real-time tracking52, 53 were less prevalent. These findings were similar to the Japanese lung SBRT survey which showed the predominance of abdominal compression for respiratory-induced motion management 7 .

Our study has a number of important limitations. We received responses from $40.1 \%$ of randomly selected, contactable physicians who represented a wide variety of demographics. Despite repeated attempts to collect responses, nonresponse and recall bias may exist. It is possible that SBRT nonusers were less likely to respond, which would lead to an overestimation of the true prevalence of SBRT use.

This study is the first to assess the usage of SBRT in the United States. We found that approximately two-thirds of surveyed physicians currently use SBRT in their clinics and the number appears to be rapidly increasing. These findings reinforce the need for prospective studies to assess the benefits and risks of this novel technology. Fortunately, several multiinstitutional phase I and II trials have been completed and Phase III trials are currently underway in the United States and Europe.

\section{Acknowledgments}

Financial Support: This work was supported in part by NIH grant 5T35HL007491-30 to HP.

\section{References}

1. Chang BK, Timmerman RD. Stereotactic body radiation therapy: a comprehensive review. Am J Clin Oncol. 2007; 30:637-644. [PubMed: 18091059]

2. Martin A, Gaya A. Stereotactic body radiotherapy: a review. Clin Oncol (R Coll Radiol). 2010; 22:157-172. [PubMed: 20092981]

3. Lax I, Blomgren H, Naslund I, Svanstrom R. Stereotactic radiotherapy of malignancies in the abdomen. Methodological aspects. Acta Oncol. 1994; 33:677-683. [PubMed: 7946448]

4. Timmerman R, Paulus R, Galvin J, et al. Stereotactic body radiation therapy for inoperable early stage lung cancer. JAMA. 2010; 303:1070-1076. [PubMed: 20233825] 
5. Gerszten PC, Burton SA, Ozhasoglu C, Welch WC. Radiosurgery for spinal metastases: clinical experience in 500 cases from a single institution. Spine (Phila Pa 1976). 2007; 32:193-199. [PubMed: 17224814]

6. Rusthoven KE, Kavanagh BD, Cardenes H, et al. Multi-institutional phase I/II trial of stereotactic body radiation therapy for liver metastases. J Clin Oncol. 2009; 27:1572-1578. [PubMed: 19255321]

7. Nagata Y, Hiraoka M, Mizowaki T, et al. Survey of stereotactic body radiation therapy in Japan by the Japan 3-D Conformal External Beam Radiotherapy Group. Int J Radiat Oncol Biol Phys. 2009; 75:343-347. [PubMed: 19735861]

8. Beitler JJ, Badine EA, El-Sayah D, et al. Stereotactic body radiation therapy for nonmetastatic lung cancer: an analysis of 75 patients treated over 5 years. Int J Radiat Oncol Biol Phys. 2006; 65:100106. [PubMed: 16517092]

9. Bradley JD, El Naqa I, Drzymala RE, Trovo M, Jones G, Denning MD. Stereotactic body radiation therapy for early-stage non-small-cell lung cancer: the pattern of failure is distant. Int J Radiat Oncol Biol Phys. 2010; 77:1146-1150. [PubMed: 19800181]

10. Chang JY, Balter PA, Dong L, et al. Stereotactic body radiation therapy in centrally and superiorly located stage I or isolated recurrent non-small-cell lung cancer. Int J Radiat Oncol Biol Phys. 2008; 72:967-971. [PubMed: 18954709]

11. Coon D, Gokhale AS, Burton SA, Heron DE, Ozhasoglu C, Christie N. Fractionated stereotactic body radiation therapy in the treatment of primary, recurrent, and metastatic lung tumors: the role of positron emission tomography/computed tomography-based treatment planning. Clin Lung Cancer. 2008; 9:217-221. [PubMed: 18650169]

12. Lagerwaard FJ, Haasbeek CJ, Smit EF, Slotman BJ, Senan S. Outcomes of risk-adapted fractionated stereotactic radiotherapy for stage I non-small-cell lung cancer. Int J Radiat Oncol Biol Phys. 2008; 70:685-692. [PubMed: 18164849]

13. Nagata Y, Negoro Y, Aoki T, et al. Clinical outcomes of 3D conformal hypofractionated single high-dose radiotherapy for one or two lung tumors using a stereotactic body frame. Int J Radiat Oncol Biol Phys. 2002; 52:1041-1046. [PubMed: 11958900]

14. Takeda A, Sanuki N, Kunieda E, et al. Stereotactic body radiotherapy for primary lung cancer at a dose of $50 \mathrm{~Gy}$ total in five fractions to the periphery of the planning target volume calculated using a superposition algorithm. Int J Radiat Oncol Biol Phys. 2009; 73:442-448. [PubMed: 18990507]

15. Uematsu M, Shioda A, Suda A, et al. Computed tomography-guided frameless stereotactic radiotherapy for stage I non-small cell lung cancer: a 5-year experience. Int J Radiat Oncol Biol Phys. 2001; 51:666-670. [PubMed: 11597807]

16. Videtic GM, Stephans K, Reddy C, et al. Intensity-modulated radiotherapy-based stereotactic body radiotherapy for medically inoperable early-stage lung cancer: excellent local control. Int J Radiat Oncol Biol Phys. 2010; 77:344-349. [PubMed: 19765913]

17. Chang EL, Shiu AS, Mendel E, et al. Phase I/II study of stereotactic body radiotherapy for spinal metastasis and its pattern of failure. J Neurosurg Spine. 2007; 7:151-160. [PubMed: 17688054]

18. Degen JW, Gagnon GJ, Voyadzis JM, et al. CyberKnife stereotactic radiosurgical treatment of spinal tumors for pain control and quality of life. J Neurosurg Spine. 2005; 2:540-549. [PubMed: 15945428]

19. Nelson JW, Yoo DS, Sampson JH, et al. Stereotactic body radiotherapy for lesions of the spine and paraspinal regions. Int J Radiat Oncol Biol Phys. 2009; 73:1369-1375. [PubMed: 19004569]

20. Sahgal A, Ames C, Chou D, et al. Stereotactic body radiotherapy is effective salvage therapy for patients with prior radiation of spinal metastases. Int J Radiat Oncol Biol Phys. 2009; 74:723-731. [PubMed: 19095374]

21. Yamada Y, Bilsky MH, Lovelock DM, et al. High-dose, single-fraction image-guided intensitymodulated radiotherapy for metastatic spinal lesions. Int J Radiat Oncol Biol Phys. 2008; 71:484490. [PubMed: 18234445]

22. Cardenes HR, Price TR, Perkins SM, et al. Phase I feasibility trial of stereotactic body radiation therapy for primary hepatocellular carcinoma. Clin Transl Oncol. 2010; 12:218-225. [PubMed: 20231127] 
23. Choi BO, Choi IB, Jang HS, et al. Stereotactic body radiation therapy with or without transarterial chemoembolization for patients with primary hepatocellular carcinoma: preliminary analysis. BMC Cancer. 2008; 8:351. [PubMed: 19038025]

24. Herfarth KK, Debus J, Lohr F, et al. Stereotactic single-dose radiation therapy of liver tumors: results of a phase I/II trial. J Clin Oncol. 2001; 19:164-170. [PubMed: 11134209]

25. Hoyer M, Roed H, Traberg Hansen A, et al. Phase II study on stereotactic body radiotherapy of colorectal metastases. Acta Oncol. 2006; 45:823-830. [PubMed: 16982546]

26. McCammon R, Schefter TE, Gaspar LE, Zaemisch R, Gravdahl D, Kavanagh B. Observation of a dose-control relationship for lung and liver tumors after stereotactic body radiation therapy. Int $\mathrm{J}$ Radiat Oncol Biol Phys. 2009; 73:112-118. [PubMed: 18786780]

27. Tse RV, Hawkins M, Lockwood G, et al. Phase I study of individualized stereotactic body radiotherapy for hepatocellular carcinoma and intrahepatic cholangiocarcinoma. J Clin Oncol. 2008; 26:657-664. [PubMed: 18172187]

28. Wulf J, Guckenberger M, Haedinger U, et al. Stereotactic radiotherapy of primary liver cancer and hepatic metastases. Acta Oncol. 2006; 45:838-847. [PubMed: 16982548]

29. Chang DT, Schellenberg D, Shen J, et al. Stereotactic radiotherapy for unresectable adenocarcinoma of the pancreas. Cancer. 2009; 115:665-672. [PubMed: 19117351]

30. Koong AC, Christofferson E, Le QT, et al. Phase II study to assess the efficacy of conventionally fractionated radiotherapy followed by a stereotactic radiosurgery boost in patients with locally advanced pancreatic cancer. Int J Radiat Oncol Biol Phys. 2005; 63:320-323. [PubMed: 16168826]

31. Koong AC, Le QT, Ho A, et al. Phase I study of stereotactic radiosurgery in patients with locally advanced pancreatic cancer. Int J Radiat Oncol Biol Phys. 2004; 58:1017-1021. [PubMed: 15001240]

32. Schellenberg D, Goodman KA, Lee F, et al. Gemcitabine chemotherapy and single-fraction stereotactic body radiotherapy for locally advanced pancreatic cancer. Int J Radiat Oncol Biol Phys. 2008; 72:678-686. [PubMed: 18395362]

33. Beitler JJ, Makara D, Silverman P, Lederman G. Definitive, high-dose-per-fraction, conformal, stereotactic external radiation for renal cell carcinoma. Am J Clin Oncol. 2004; 27:646-648. [PubMed: 15577450]

34. Chawla S, Chen Y, Katz AW, et al. Stereotactic body radiotherapy for treatment of adrenal metastases. Int J Radiat Oncol Biol Phys. 2009; 75:71-75. [PubMed: 19250766]

35. Svedman C, Karlsson K, Rutkowska E, et al. Stereotactic body radiotherapy of primary and metastatic renal lesions for patients with only one functioning kidney. Acta Oncol. 2008; 47:15781583. [PubMed: 18607859]

36. Wersall PJ, Blomgren H, Lax I, et al. Extracranial stereotactic radiotherapy for primary and metastatic renal cell carcinoma. Radiother Oncol. 2005; 77:88-95. [PubMed: 15972239]

37. Friedland JL, Freeman DE, Masterson-McGary ME, Spellberg DM. Stereotactic body radiotherapy: an emerging treatment approach for localized prostate cancer. Technol Cancer Res Treat. 2009; 8:387-392. [PubMed: 19754215]

38. Fuller DB, Naitoh J, Lee C, Hardy S, Jin H. Virtual HDR CyberKnife treatment for localized prostatic carcinoma: dosimetry comparison with HDR brachytherapy and preliminary clinical observations. Int J Radiat Oncol Biol Phys. 2008; 70:1588-1597. [PubMed: 18374232]

39. Katz AJ, Santoro M, Ashley R, Diblasio F, Witten M. Stereotactic body radiotherapy for organconfined prostate cancer. BMC Urol. 2010; 10:1. [PubMed: 20122161]

40. King CR, Brooks JD, Gill H, Pawlicki T, Cotrutz C, Presti JC Jr. Stereotactic body radiotherapy for localized prostate cancer: interim results of a prospective phase II clinical trial. Int J Radiat Oncol Biol Phys. 2009; 73:1043-1048. [PubMed: 18755555]

41. Madsen BL, Hsi RA, Pham HT, Fowler JF, Esagui L, Corman J. Stereotactic hypofractionated accurate radiotherapy of the prostate (SHARP), 33.5 Gy in five fractions for localized disease: first clinical trial results. Int J Radiat Oncol Biol Phys. 2007; 67:1099-1105. [PubMed: 17336216]

42. Buyyounouski MK, Price RA Jr. Harris EE, et al. Stereotactic body radiotherapy for primary management of early-stage, low- to intermediate-risk prostate cancer: report of the American 
Society for Therapeutic Radiology and Oncology Emerging Technology Committee. Int J Radiat Oncol Biol Phys. 2010; 76:1297-1304. [PubMed: 20338473]

43. Simpson DR, Lawson JD, Nath SK, Rose BS, Mundt AJ, Mell LK. Utilization of advanced imaging technologies for target delineation in radiation oncology. J Am Coll Radiol. 2009; 6:876883. [PubMed: 19945044]

44. Simpson DR, Lawson JD, Nath SK, Rose BS, Mundt AJ, Mell LK. A survey of image-guided radiation therapy use in the United States. Cancer. 2010; 116:3953-3960. [PubMed: 20564090]

45. Jiang SB, Wolfgang J, Mageras GS. Quality assurance challenges for motion-adaptive radiation therapy: gating, breath holding, and four-dimensional computed tomography. Int J Radiat Oncol Biol Phys. 2008; 71:S103-107. [PubMed: 18406905]

46. Keall PJ, Mageras GS, Balter JM, et al. The management of respiratory motion in radiation oncology report of AAPM Task Group 76. Med Phys. 2006; 33:3874-3900. [PubMed: 17089851]

47. Keall PJ, Kini VR, Vedam SS, Mohan R. Potential radiotherapy improvements with respiratory gating. Australas Phys Eng Sci Med. 2002; 25:1-6. [PubMed: 12049470]

48. De La Fuente Herman T, Vlachaki MT, Herman TS, Hibbitts K, Stoner JA, Ahmad S. Stereotactic body radiation therapy (SBRT) and respiratory gating in lung cancer: dosimetric and radiobiological considerations. J Appl Clin Med Phys. 2010; 11:3133. [PubMed: 20160698]

49. Negoro Y, Nagata Y, Aoki T, et al. The effectiveness of an immobilization device in conformal radiotherapy for lung tumor: reduction of respiratory tumor movement and evaluation of the daily setup accuracy. Int J Radiat Oncol Biol Phys. 2001; 50:889-898. [PubMed: 11429216]

50. Wunderink W, Mendez Romero A, de Kruijf W, de Boer H, Levendag P, Heijmen B. Reduction of respiratory liver tumor motion by abdominal compression in stereotactic body frame, analyzed by tracking fiducial markers implanted in liver. Int J Radiat Oncol Biol Phys. 2008; 71:907-915. [PubMed: 18514783]

51. Gagel B, Demirel C, Kientopf A, et al. Active breathing control (ABC): determination and reduction of breathing-induced organ motion in the chest. Int J Radiat Oncol Biol Phys. 2007; 67:742-749. [PubMed: 17197133]

52. D'Souza WD, Naqvi SA, Yu CX. Real-time intra-fraction-motion tracking using the treatment couch: a feasibility study. Phys Med Biol. 2005; 50:4021-4033. [PubMed: 16177527]

53. Sawant A, Venkat R, Srivastava V, et al. Management of three-dimensional intrafraction motion through real-time DMLC tracking. Med Phys. 2008; 35:2050-2061. [PubMed: 18561681] 


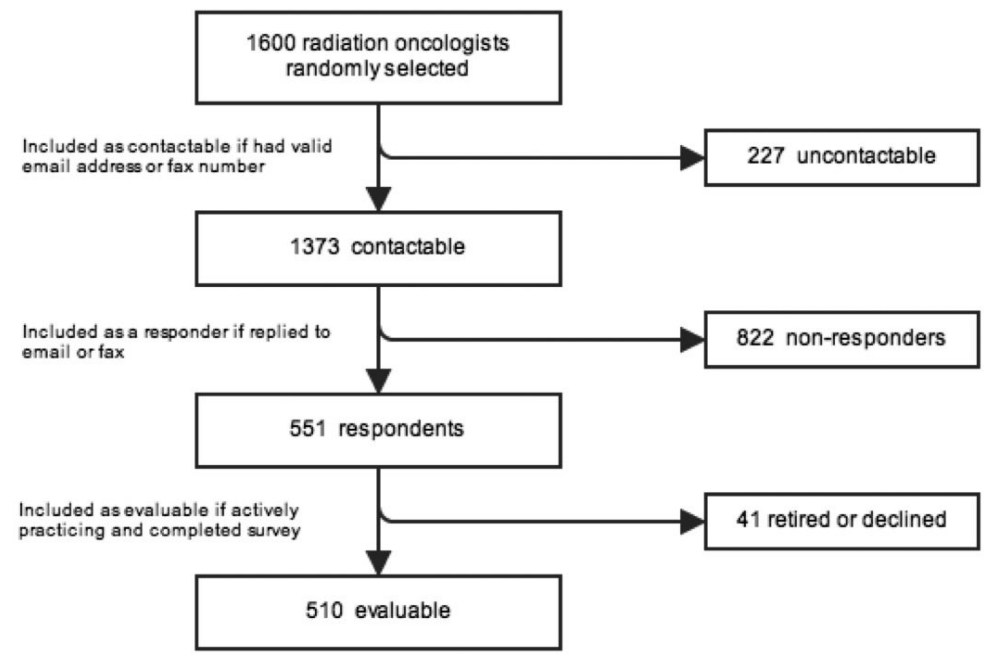

Figure 1.

Flowchart of the stereotactic body radiation therapy (SBRT) survey respondents. 


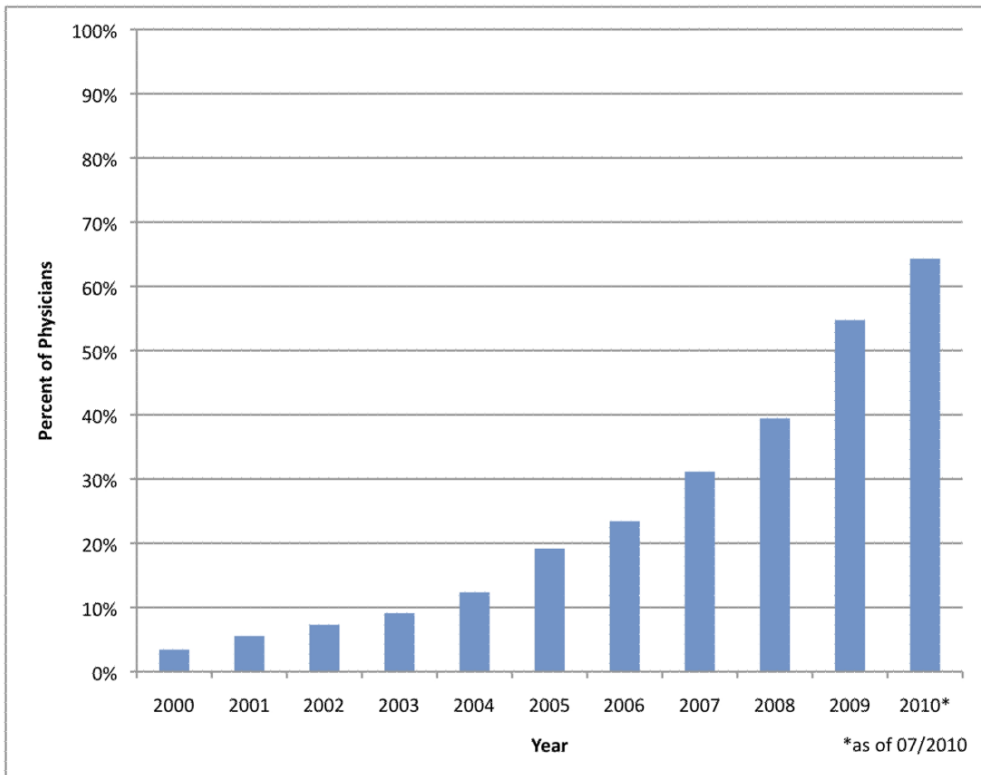

Figure 2.

Cumulative adoption of stereotactic body radiation therapy (SBRT) for the treatment of any disease site. 


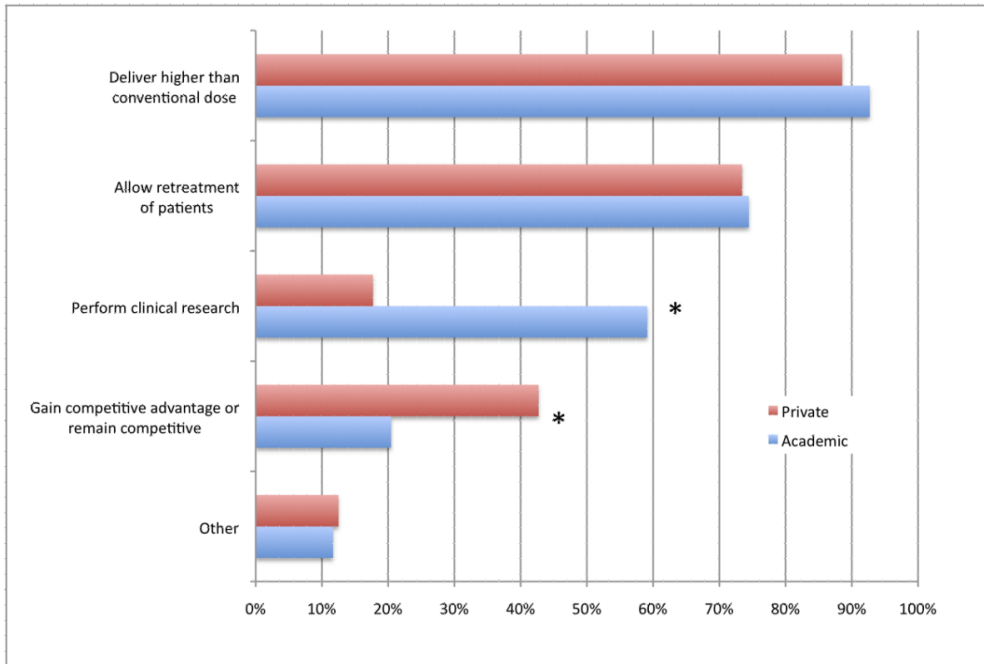

Figure 3.

Reasons cited by academic and private practice physicians for adopting stereotactic body radiation therapy (SBRT). Asterisks denote $\mathrm{P}<0.05$. 


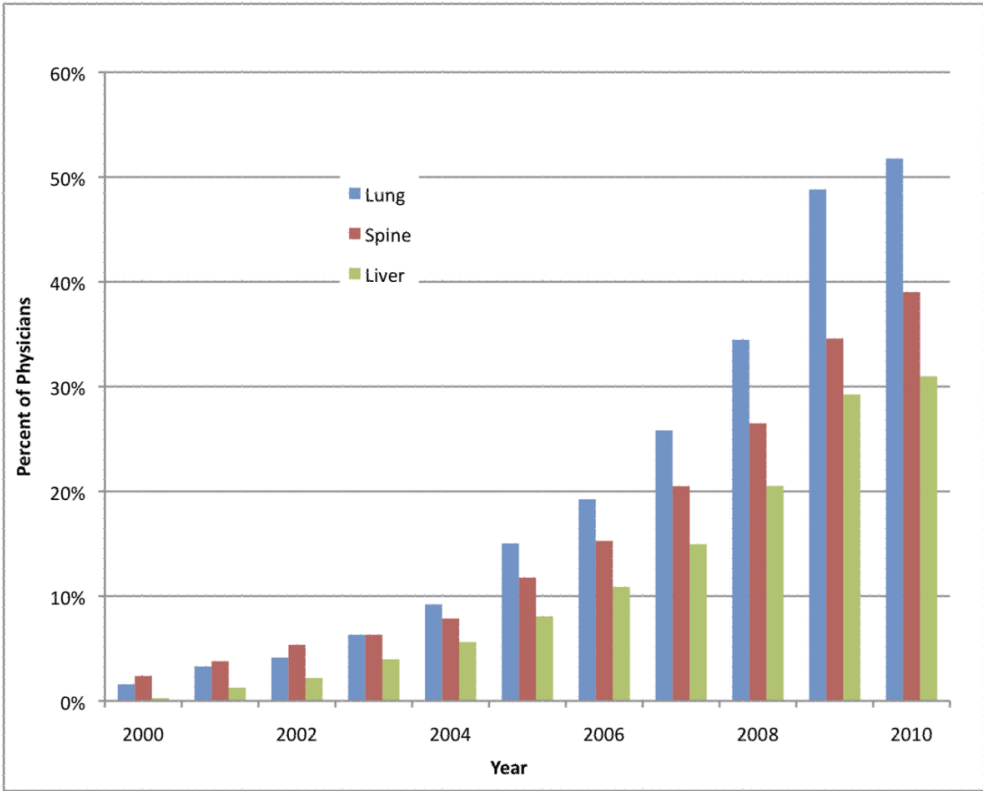

Figure 4.

Cumulative adoption of stereotactic body radiation therapy (SBRT) for the three most common disease sites treated: lung, spine, and liver. 


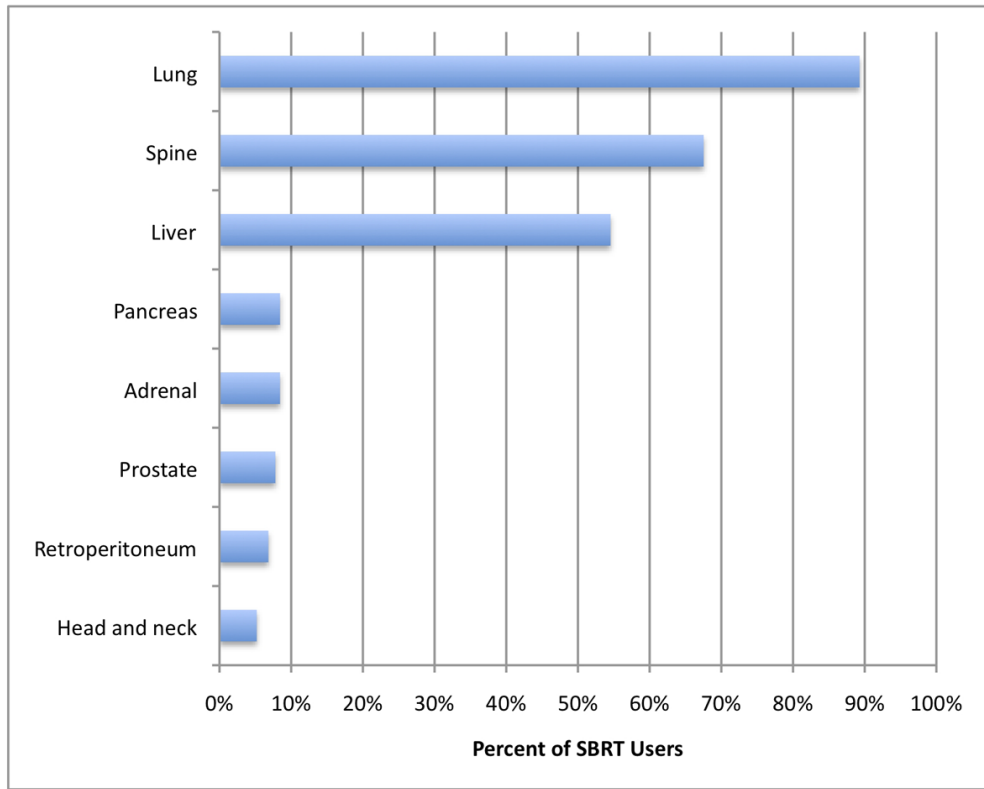

Figure 5.

Disease sites treated by stereotactic body radiation therapy (SBRT) users that responded to the survey. 


\section{Table 1}

Characteristics of Physician Respondents

\begin{tabular}{lc} 
Characteristic & No. Respondents (\%) \\
No. of physicians & 510 \\
Geographic location ${ }^{a}$ & \\
$\quad$ Midwest & $145(28.4)$ \\
South & $129(25.3)$ \\
East & $117(22.9)$ \\
West & $117(22.9)$ \\
Unknown & $2(0.4)$ \\
Practice Type & \\
Academic & $191(37.5)$ \\
Private & $319(62.5)$ \\
Specialist $b$ & $180(35.3)$ \\
Median time in practice (range), y & $16(1-31)$ \\
Median no. physicians in practice (range) & $5(1-60)$ \\
\hline
\end{tabular}

${ }^{a}$ East: CT, DC, DE, ME, MD, MA, NH, NJ, NY, PA, RI, VT, WV; Midwest: IL, IN, IA, KS, KY, MI, MN, MO, NE, ND, OH, OK, SD, WI; South: AL, AR, FL, GA, LA, MS, NC, SC, TN, TX, VA; West: AK, AZ, CA, CO, HI, ID, MT, NV, NM, OR, UT, WA, WY

${ }^{b}$ Specialist: central nervous system, breast, lung, prostate, others 
Table 2

Most commonly reported SBRT prescriptions for lung, spine, and liver tumors

\begin{tabular}{lllll} 
& $\begin{array}{l}\text { Fractions } \\
(\boldsymbol{\%})\end{array}$ & $\begin{array}{l}\text { Common Dose/Fraction, } \\
\text { Gy }(\%)\end{array}$ & $\begin{array}{l}\text { Median } \\
\text { Dose/Fraction, Gy } \\
\text { (range) }\end{array}$ & $\begin{array}{l}\text { Median IDL } \\
\text { \% (range) }\end{array}$ \\
Lung (n=262) & $3(47 \%)$ & $20(46 \%), 18(45 \%)$ & $18(10-20)$ & $80(70-100)$ \\
& $4(21 \%)$ & $12(78 \%), 12.5(11 \%)$ & $12(10-16)$ & $85(80-100)$ \\
Spine (n=170) & $5(37 \%)$ & $10(51 \%), 12(34 \%)$ & $10(3-20)$ & $90(75-100)$ \\
& $3(22 \%)$ & $8(51 \%), 7(14 \%)$ & $18(7-24)$ & $85(70-100)$ \\
& $5(18 \%)$ & $6(60 \%), 7(10 \%)$ & $6(4-12)$ & $80(75-95)$ \\
Liver (n=142) & $3(48 \%)$ & $15(40 \%), 20(25 \%)$ & $15(8-20)$ & $100(90-100)$ \\
& $4(9 \%)$ & $12(77 \%), 10(8 \%)$ & $12(8-12)$ & $80(70-100)$ \\
& $5(38 \%)$ & $10(38 \%), 12(19 \%)$ & $10(5-12)$ & $90(70-100)$ \\
\hline
\end{tabular}

$a_{\text {IDL: isodose line. }}$ 